\title{
Overseeing From Overseas: The Role of ICT in Sustaining Parental Relationships
}

\author{
${ }^{1}$ Ma. Concepcion R. Repalam, ${ }^{2}$ Ruby B. Brion $\&{ }^{3}$ Angela L. Reginaldo
}

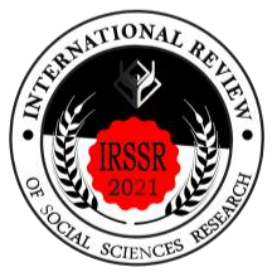

\begin{abstract}
The study investigates the role of information and communication technology (ICT) in sustaining parental relationships among Overseas Filipino Workers (OFW) families. Specifically, the study sought to determine the communication tools and its usage in terms of frequency, features and mode. It also tested any significant relationship between ICT usage and the degree of family closeness. The theories, Bowen Family Theory and the Media Richness Theory, were integrated to gather data from the purposively chosen students of Laguna State Polytechnic University with one or both parents are OFWs for at least one year. Results revealed that laptops and mobile phones are mostly used by the families as communication tools while Facebook is the most popular online platform because of the variety of features. The study also revealed a significant relationship between the perceived role of ICT tools with the degree of closeness of the family. Parents mostly initiate communication, indicating their desire to strengthen the closeness of the family. Their leftbehind children, however, do not fully share details about their life, causing them to have a distant relationship. Further studies can provide more relevant information that can be used in the development of migrant workers and their families.
\end{abstract}

Keywords:

ICT, Overseas Filipino workers, migration, parental relationships

Suggested Citation: Repalam, M.R., Brion, R.B. \& Reginaldo, A.L. (2021). Overseeing From Overseas: The Role of ICT in Sustaining Parental Relationships. International Review of Social Sciences Research, Volume 1, Issue 3, pp. 25-47.

\footnotetext{
About the authors:

${ }^{1}$ Corresponding author. Assistant Professor III, Laguna State Polytechnic University- San Pablo City Campus

${ }^{2}$ Associate Professor II, Laguna State Polytechnic University- San Pablo City Campus

${ }^{3}$ Assistant Professor IV, Laguna State Polytechnic University- San Pablo City Campus
} 


\section{Introduction}

A family is an important social unit. A person's culture and conduct are developed in the family which can have an impact on the society in which they live. Parents take the lead in instilling good manners and values in their children in order for them to grow into productive adults. As specified in the Convention on the Rights of the Child (CRC), parents have the legal responsibility of providing "appropriate direction and guidance" to their children. Being a parent is a lifetime commitment. They gave life to their children, provide food, medical care, shelter, and clothing, as well as give love, compassion, and encouragement. They are their role models, setting a good example for the moral values that their children should learn and carry as they become adults.

Parents serve as a mediator to resolve a conflict that family members experience (Dugue, et.al., 2017). They also exert control over their children through enforcing discipline, establishing rules and boundaries, and holding them accountable for their behaviors and decisions ("Role of Parents", n.d). As their children get older, parents take the role of counselors in their life choices and decisions. Parents should always be present at every stage of their child's life. When parents are unable to be physically present with their children such as when they work abroad, indigeneity problems arise. Various issues such as violent behavior, child rebellion, drug addiction, depression, broken marriages, and teen pregnancy have been prevalent, especially during the 1980s when overseas employment was highest (Alampay, et.al, 2017).

An increasing number of Filipinos are leaving the country in search of better opportunities abroad (Reyes, 2008). According to the Philippine Statistics Authority (PSA), an estimated 2.2 million Filipinos worked overseas in 2019. The majority were women who worked as nurses, cleaners, and nannies, hoping to give their children a better future (Rocamora, 2019; Yeung \& Bacani, 2020). The high unemployment rate in the country also pushes skilled workers - welders, carpenters, construction workers, teachers, etc. - to find employment abroad for higher salaries (“OFWs are Heroes of PH Economy”, 2019; "OFWs

- The Strong Pillars Of The Philippine Economy”, 2019) and financial security (Harper \& Martin, 2012) at the expense of leaving their loved ones. 
While working abroad has significant financial advantages, it is impossible to deny the sacrifices that OFWs are enduring away from their families. These modern-day heroes have to overcome homesickness, communication gaps (Bautista \& Tamayo, 2020), biased working conditions (Ofreneo \& Samonte, 2005), cultural differences and, even maltreatment (Sayres, n.d.) in order to provide for their family's needs. They miss important events, like birthdays and graduations, to save more money and send it back to their family. They forego their own personal needs in exchange for a better life for their loved ones. They risk their health, at the same time, worry about their family's health (Pogoy \& Cutamora, 2021). Sometimes, the bond they have with their children are broken and damaged because of the separation (Yeung \& Bacani, 2020).

One of the fundamental factors that play a vital role in the parent-child relationship is communication. For communication to become effective, one should be able to listen, be accessible and able to comprehend what is being said. It establishes and maintains the relationship between parents and children, makes the parent-child interaction successful and strong, and helps parents and children understand and accept each other (Runcan, et.al. 2012). With the advent of the Internet and social media, parents no longer see the physical distance as a hindrance in doing their responsibility to their families who are left behind. For them, it is their commitment to constantly communicate so that their children will not feel neglected and alone while they are millions of miles away.

This research aims to determine the role that information and communication technology (ICT) play in the parental relationship of OFW families. In particular, the researchers explored the different communication tools used by the OFW families, its frequency of use, and features most used. Furthermore, the researchers evaluated whether the degree of closeness of the family has a significant relationship with the usage of these communication tools.

This research is conducted at the Laguna State Polytechnic University - San Pablo City campus (LSPU - SPC), a state university in the province of Laguna. It has four major campuses and several auxiliary campuses. The students from this campus hail from different areas in Region IV - A which is where the majority of OFWs also come from (PSA, 2019). 
Thus, this study provides a baseline data on the development of migrant workers and their families. Understanding the impact that ICT has on parental relationships could uncover future researches that will help in the improvement of OFW and their families' well-being.

\section{Literature review}

\subsection{Overseas Filipino Workers (OFW) Profile}

The Revised Philippine Overseas Employment Administration (POEA) rules and regulations governing the recruitment and employment of land-based OFWs of 2016 defined an OFW as " $a$ contract worker with employment contract/offer of employment already processed by the POEA for overseas deployment, whether as an agency hire or a directhire". The overall number of OFWs who worked abroad at any time between April and September 2019 was projected to be 2.2 million by PSA's 2019 Survey on Overseas Filipinos (SOF), with $96.8 \%$ of them having current contracts during the same period. Female OFWs account for 56.0 percent while male OFWs are at 44.0 percent. Around $60 \%$ of OFWs are between the age of 25 - 39 years old. The majority of OFWs come from Region IV-A (CALABARZON) which accounts for 20.7 percent, followed by Region III (Central Luzon), which accounts for 13.3 percent. Saudi Arabia, with one out of every five (22.4 percent) OFWs working there, and the United Arab Emirates (UAE), with 13.2 percent, remain the leading country destinations from 2017 to 2019, however both are dropping over time. Other destinations such as Hongkong, Taiwan, and Europe have seen an increase within the same time period. During the months of April to September 2019, OFWs sent a total of Php 211.9 billion in remittances. This includes cash that was sent home, cash that was brought home and remittances in kind.

\subsection{Labor migration in the Philippines}

Labor migration has long been an option for Filipino families to increase their income flow and raise their standard of living. This is the impact of globalization to Philippine households. Because of political instability, unemployment, growing population and low wages (Estrada, 2015), the Philippines has seen an increase in migrant workers.

Filipinos have been migrating since the turn of the $20^{\text {th }}$ century. Low-skilled agricultural workers from Ilocos initially migrated to Hawaii and later, movement shifted to 
the United States and Alaska. But it was in the 1970s, when Middle East started contracting workers to work in their oil rigs and construction sites that migration has come full circle. "Katas ng Saudi" became a popular phrase when families receive care packages in balikbayan boxes or their life improves as a result of working in Saudi Arabia (Santos, 2014). In the 80 s and 90s, women began filling the service needs of other countries in and around Asia. The Asian market share of deployed overseas workers rose steadily and significantly from 1.29 percent in 1983 to 25 percent in 1989 to 1990 . Today, labor migration in the Philippines is more diverse and intense as they have made working abroad common and desirable. Filipinos are now one of the major exporters of workers, dominating the seafaring, domestic work and nursing sectors, among others, all over the world.

The decision to work abroad was brought about by the pressing unemployment and underemployment in the Philippines. A significant portion of the population is discontent with the country's current situation, and the perception that "greener pastures" are forthcoming abroad, are some of the factors for the decision to migrate. With higher salary and better working conditions (Pastera, 2014), OFWs can improve the financial situation of their left-behind family that translates to providing for the needs and wants of their children and other family members (Teguihanon and Cuaton, 2020).

\subsection{Information and Communication Technology}

ICT is a broad term that covers a wide range of technological tools used to handle communication processes. These tools include computers, the Internet, wireless networks, landline or mobile phones, video-conferencing, social networking, and other media applications and services enabling users to access, retrieve, store, transmit, and manipulate information in a digital form.

ICTs entails far more than just information access or computer technology. ICTs influence how an individual, a family, a business, or a country accesses information, people, services, and technology. Because of ICT, people has not only altered how they get the information, but also how it is used, depending on the amount and availability of information at any given time. It has also change how people relate to one another, in terms of their 
association in the digital world. It has the ability to both link and isolate people (Dutton, 2001).

Communication with loved ones during the 80 s and 90 s is done through snail mail, voice tape, telephone, and mobile phone (Bernarte, et. al. 2015). Using these methods take a long time to receive a response and is also costly therefore messages must be kept short. Families now have more communication time because of modern and less expensive communication technology. Face-to-face communication was shown to be the most common means for sharing information about family life, followed by instant messaging, phone, social media sites, video calls and email (Shen, 2017). According to the same findings, a combination of face-to-face and video calls was also strongly associated with improved family well-being. Because the parent and child can see each other's faces, the experience becomes more interactive and personal. This is especially beneficial for parents who have left-behind infants and toddlers who are not yet speaking fluently.

The 2019 National ICT Household Survey conducted by the Department of Information and Communication Technology (DICT) in collaboration with the Philippine Statistical Research and Training Institute (PSRTI) and Philippine Statistics Authority (PSA) found that 24 percent of households have a communal mobile phone and only 8.2 percent have their own telephone lines. In terms of utilization, about 79 percent men and women, aged 10 and above had used a cellular phone. Eighty-nine percent of them have only one unit, while the rest have more than one. According to a Microsoft survey, Filipino families have the highest number of gadgets in the region, with an average of ten devices used to communicate with loved ones in other parts of the country and the world (Ho, 2011).

The NICTHS also reported that only two out of ten have communal computers, yet approximately 34 percent have used a computer. The desktop computer is the most commonly used (44\%); while 39 percent said they use a laptop and 22 percent reported they use a tablet computer. Almost 69 percent of all computer users use computers primarily for communication purposes. Interestingly, women (77\%) outnumber men $(66 \%)$ in their usage of computers for social interaction. The report also showed that 63 percent of Filipino users said that they use the computer for entertainment and gaming, 23 percent use them for 
sending electronic mail and 22 percent of all users said that they used computers for online courses.

The internet has revolutionized communication in this generation. Using this technology, people can instantly share photos, post news and stories, and chat with friends and family anywhere around the world. Communication has become more fluid because of the internet. Digital 2021 reported that there are 73.91 million internet users in the Philippines in January 2021, 77.3 percent access the internet via laptops or desktop computers. The same survey also showed that mobile phones (98.6\%), smartphones (98.5\%), and tablet devices $(33.2 \%)$ were also utilized to access the internet. This is in contrast with the NICTHS report that around 47 percent individuals aged 10 and above, use the internet and many of them have used a cellphone to connect to the internet (85\%). This is followed by desktop computer (30\%), laptop computer (19\%) and tablet devices (7\%). However, the NICTHS also reported that 17.7 percent of households have their own internet access at home, majority of which use it for social media and communication. Statista (2020) forecasted that by 2025 , there would be an estimated 77.1 percent of the population using the internet.

In terms of social media statistics, there are 89 million social media users in the Philippines in January 2021, which is equivalent to $80.7 \%$ of the population (Digital, 2021). According to Statista (2020), the Philippines has the highest number of social network users in Southeast Asia, with a penetration rate of approximately 67 percent during the same period. The report also showed that Filipinos spend an average of four hours each day on social media, which bridged the distance with family and friends. Among the social media users, Facebook was the most used platform, which accounted for almost 93 percent of the social media market and 99 percent of the internet users, as of June 2020. Facebook users are mostly between 18 to 24 years old. said they read messages and posts, look at photos, and chat with their loved ones abroad. Twitter is a far second with 2.99 percent of the population using the platform.

In terms of electronic mail, there is about 3.8 billion email accounts around the world at the start of 2019. Many young people have at least two email accounts. Millennials spend 
about 6.4 hours a day using email, which they have adapted for their personal and professional use (Internet World Stats, 2019).

\subsection{Theoretical framework}

This study is based on the integration of several theories, the Bowen Family Systems Theory and the Media Richness Theory.

Bowen family systems theory is an approach of human behavior that views the family as a single emotional unit and that the individual members and the group as a whole can influence each other's functioning. There is a strong emotional connection among members of the family. They affect each other's thoughts, feelings, and actions and seeks each other's attention, approval, and support. They react to each other's needs, expectations, and disappointments. Each member plays a specific role and must follow rules. Even if the family is disconnected, the members still have an impact on each other's emotions. Families differ in their degree of interdependence, but the connection is always present to some degree.

\section{Figure 1.}

The Bowen Family Systems Theory

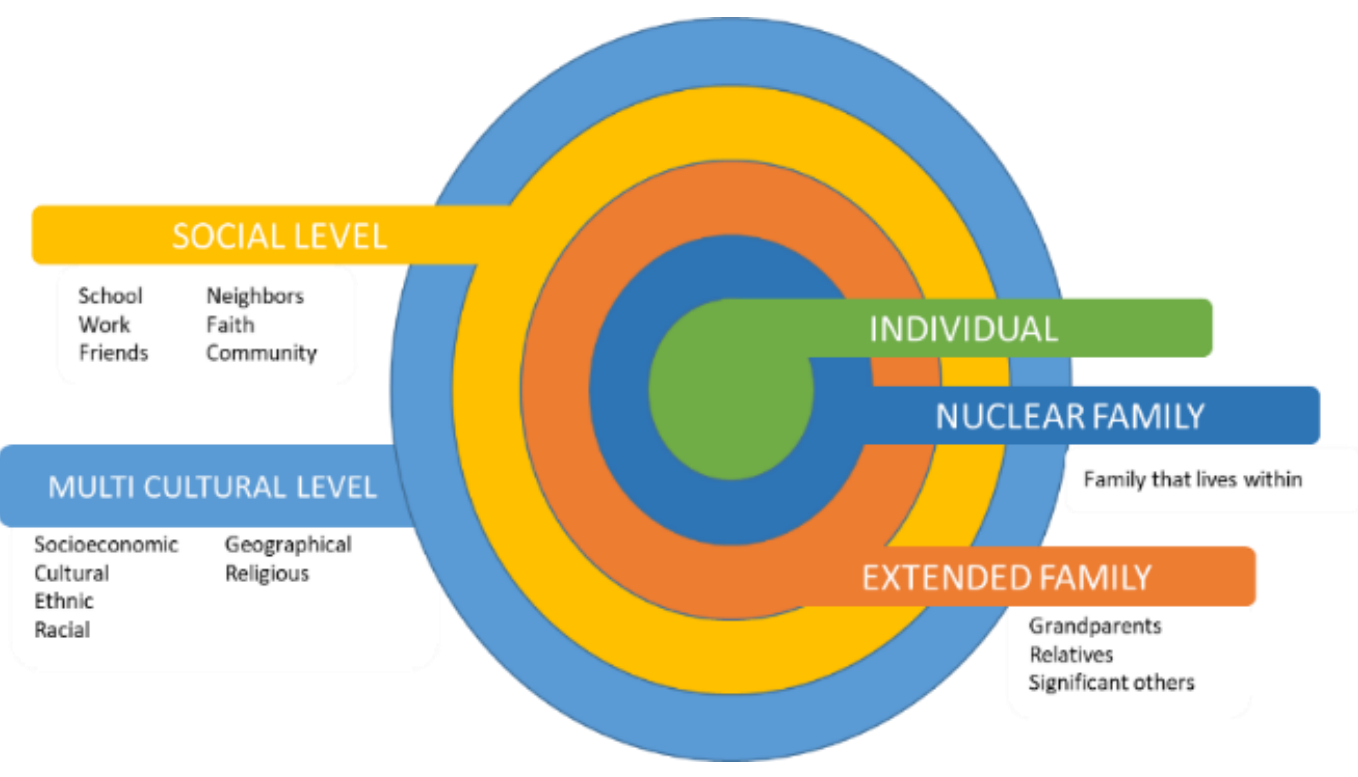

Source: https://empoweredlivingcounseling.weebly.com/introduction-to-family-systems-theory.html 
The Bowen family Systems Theory is depicted in Figure 1. It is explained that the family is a strongly connected emotional unit made up of individual members. Everything that a member of the family acts or feels has an impact on the rest of the unit. A typically Filipino family consists of a father, a mother and their children. It may be extended to grandparents, aunts and uncles, and in - laws. The family lives in a community. They have regular interactions with their neighbors, friends, classmates, and workmates, among others. The family is also part of a community with beliefs and culture that influences who they are as individuals and as a group.

When there is a change in the normalcy of the unit, each of the member senses it and reacts to this change. When a parent makes the decision to work abroad, the normalcy of their family will change. One family member will be physically absent and the children will feel this void. Members who are left-behind will have to adjust to this separation and cope with the difficulties (Shih, 2016). The other parent may act as both mother and father (Graham, et.al., 2012). If a member of the extended family, such as an aunt or grandparent, takes the role as the "parent", they may have an impact on the development of the children, which may result in issues with psychological development, adjustment, and educational functioning (Edwards \& Mumford, 2005). Children's academic performance may be impacted as well (Lu, 2014; Mao, Zang \& Zhang, 2020; Marchetta \& Sokcheng, et. al., 2019).

Constant communication between parents and children is required to maintain a normal parenting relationship. Simulating a normal parental relationship in OFW families is dependent on the efficacy of the communication medium. In describing the results, the researchers used media richness theory and family systems theory.

The media richness theory is a framework for assessing the efficacy of communication mediums such as phone conversations, video conferencing and email. The ability of all communication media to allow users to transmit complex messages varies

Messages can be communicated in several levels (Figure 2). A text message can send and receive less information than an email or phone conversation. As the level progresses, 
the amount of information increases therefore increasing the amount of understanding. There is also a lesser chance of being misunderstood.

Communication through texting has the least amount of richness and is most likely to be misread. Texting contains a shorter version of the language with a lot of acronyms and phonetic techniques of shortening words/phrases for convenience and speed.

Figure 2

Media Richness Theory

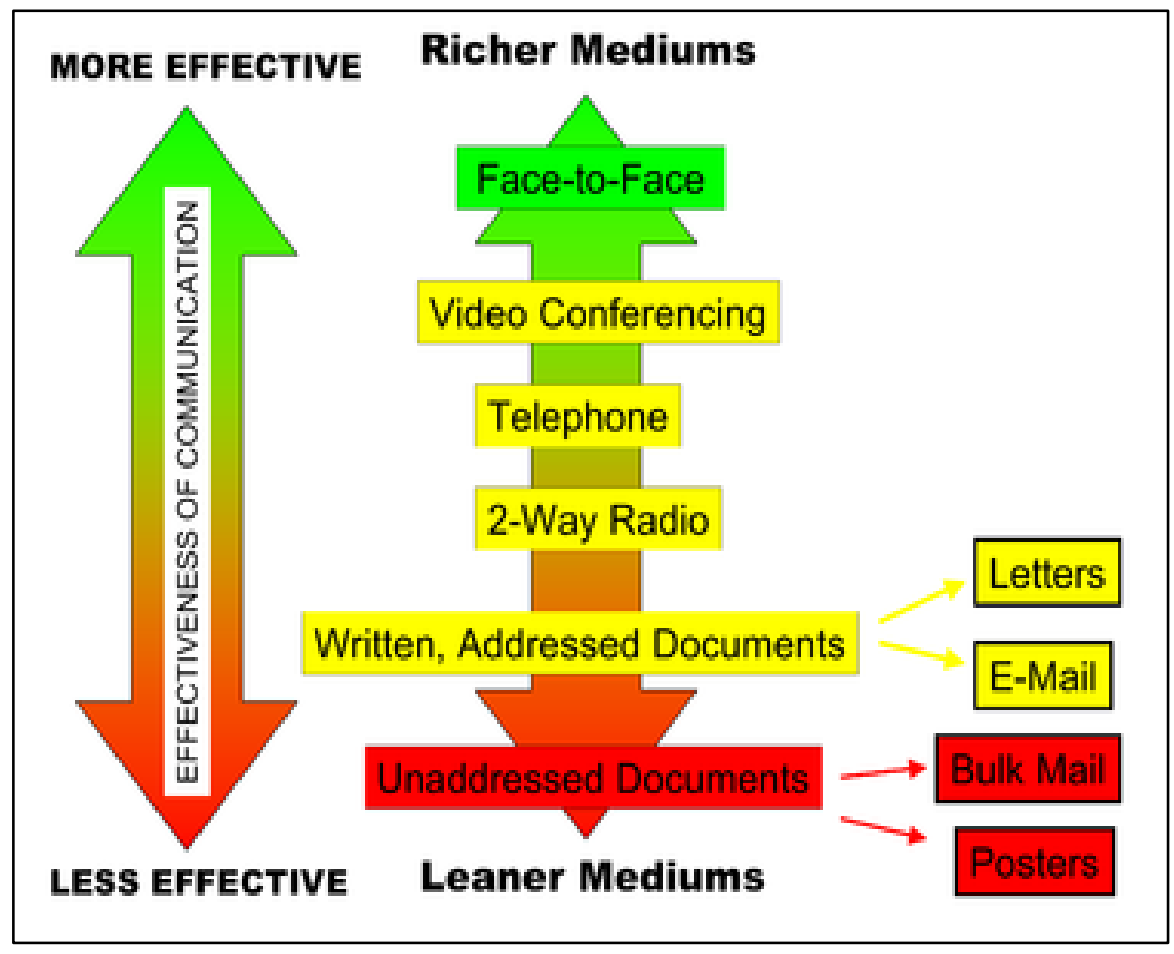

Source: Daft, R.L.; Lengel, R.H. (1986). "Organizational information requirements, media richness and structural design". Management Science. 32 (5): 554-571.

According to the theory, face to face communication is still the most efficient way to convey a message, such as parental advice. However, when face to face contact is not possible, transnational parents are able to find ways to still connect and interact with the children they left behind. They are able to reinvent parenthood by utilizing the different communication media. Text messaging is a popular medium because it is convenient, messages can be dispersed quickly and responses can be received immediately. This capability is now available on all mobile phones, making it versatile and readily available. It is considered to be a leaner medium of communication since it is prone to misinterpretation. 
Because text messages have limited space, the amount of information that may be sent is likewise limited. Letters and emails are more enriched form of media. Using these media, longer messages can be written. Letters are more personal since they are hand written, so the recipient can feel the importance of the message being conveyed. Email, on the other hand, is fast. If children want to send a lengthy message to their OFW parents, the fastest way to do it is through email. Email attachments may also be used to further understand the message. However, an internet connection is required to send and receive emails. The telephone is in the next level of rich media. Through a telephone conversation, parents and children can communicate more effectively. Because it is two-way, there is immediate feedback from the receiver of the message. Clarifications can be made right away to avoid misunderstanding. Cellular phones provide portability and accessibility to one another. Parents and children can just dial the number and they will be able to talk to each other right away. It can also be used anytime and from any location. Video conferencing or video calls are richest media of communication because of the ability to see each other while communicating. Through video calls, parents can monitor the status of their children. They can observe their behavior, they can see how they smile and hear them laugh and they can share moments with each other.

Integrating these two theories would help the researchers in understanding how parents can sustain their relationship with their children while they are apart.

\section{Methodology}

The study used the descriptive design of research. This method is used to obtain information concerning the current status of the facts to describe what exists with respect to variables or conditions in a situation. It is a quantitative kind of research to understand a certain research problem from the perspective of the subjects (Burns and Grove, 2005).

The study was conducted at the Laguna State Polytechnic University-San Pablo City Campus (LSPU-SPCC), using purposive sampling. Eighty nine students who have parents working abroad were given questionnaires. They were chosen based on the following criteria: (1) they are bonafide college students studying in LSPU - SPCC whose parents are working abroad for more than a year. (2) OFW parents could be mothers, fathers, or both; and (3) the student must still be in contact with his/her parents. Respondents' age ranges 
from 17 to 21 years old. Fifty - four are female, while thirty - five are male respondents. They are all single but it is interesting to note that sixteen of them are single parents. According to Fluellen (2016), there is a major issue of poverty among female headed household. To improve their quality of life, single mothers pursue to continue their education. Moreover, Fluellen stated that these single mothers receive motivation from their own parents.

To interpret the gathered data, the researchers used different statistical methods including frequency and percent distribution. Pearson Product Moment Correlation (Pearsonr) was used to determine the relationship between the involvement of students in social media and in sustaining their relationship with their families.

\section{Findings and Discussion}

\subsection{Communication Tools Used by OFW Families}

New communication technologies, such as internet and mobile phones, allow mothers to experience their parental relationship remotely (Madianou, 2012). Samonte (2018) found that the choice of communication medium is dependent on four factors: the socio-economic status of the family, location of the parent(s), availability of the communication media and features of the communication media.

Table 1

Communication Tools used by OFW families and its Frequency (Hardware)

\begin{tabular}{llccccc}
\hline Categories & $\begin{array}{l}\text { Communication } \\
\text { Tools }\end{array}$ & $\begin{array}{c}\text { Never used at } \\
\text { all }\end{array}$ & Rarely & Average & Often & All of the time \\
\hline Traditional & Desktop & 0 & 2 & 4 & 0 & 34 \\
& Laptop & 0 & 4 & 18 & 0 & 56 \\
& Phone / Landline & 20 & 2 & 6 & 12 & 48 \\
& Snail Mail & 89 & 0 & 0 & 0 & 0 \\
\hline \multirow{2}{*}{ Modern } & Smart Phone & 0 & 0 & 0 & 0 & 89 \\
& Tablet & 0 & 0 & 12 & 15 & 59
\end{tabular}

Respondents were asked what tools their parents use in communicating with them. The tools were categorized as traditional and modern tools. Traditional communication tools include desktop, laptop, landlines or telephones and snail mail, while smart phones and tablets are categorized as modern communication tools. Table 1 indicates that the 
respondents are still using the traditional as well as modern communication tools whenever they communicate with their family. In terms of traditional tools, laptops are the most frequently used. Laptops are preferred over other devices because it is portable. It has the same function as the desktop but it can be carried around outside the house. Landline phones are also popular among respondents possibly because it has a more stable signal compared to cellular phones. It can also be used even without electricity, which makes it more reliable for communication. There were none who used the snail mail anymore. Respondents are not used to the pen and paper type of communication and prefers electronic devices over manual type.

For modern communication tools, all 89 respondents use cellular phones to interact with their family all the time, while 59 respondents use tablets. Smart phones are more portable than traditional communication tools. They are versatile devices due to numerous capabilities they have such as texting and calling. These provide OFW parents to still portray their roles even when there are geographical constraints that separate them. (Madianou and Miller, 2011). Chen (2020) referred to it as mediated family gaze. Based on the media richness theory, text messages are effective communication medium because of its convenience and availability. Messages can be sent and received immediately using text. They also use these devices to collect information and track the welfare of their left-behind children (Madianou, 2016). Aside from that, there are applications in mobile devices that allows OFW parents to transfer money to address financial needs of family members or as gifts (Fresnoza - Flot 2009; Madianou and Miller 2012).

In 2015, the number of mobile phone users in the Philippines was about 66 million (Statista, 2016). It is considered as an essential consumer product. Statista found that Filipinos still allocate amounts for communication spending even when expenditure is mostly concentrated on food and beverage. Telephone calls and mobile calls are more personal because both parties can hear each other's voice and feel their emotions (Samonte, 2018).

Results show that we have embraced technology as a means of communication. As technology becomes more available and affordable, more OFW families will be using these devices to bridge the relationship gap. 


\subsection{Communication Tools used by OFW families and its Frequency (Software}

\section{Application)}

In terms of software applications, the options presented include different social media platforms (Facebook, Skype and Twitter), email providers (Yahoo Mail and Gmail), and other communication tools (Text, cellular phone calls and landline phone calls).

Table 2

Communication Tools used by OFW families and its Frequency (Software and Application)

\begin{tabular}{lccccc}
\hline Communication Tools & Never used at all & Rarely & Average & Often & All of the time \\
\hline Facebook & 0 & 2 & 3 & 6 & 78 \\
Skype & 46 & 15 & 5 & 20 & 3 \\
Twitter & 7 & 10 & 14 & 23 & 35 \\
Yahoo Mail & 0 & 2 & 5 & 6 & 40 \\
Gmail & 1 & 6 & 10 & 1 & 18 \\
Text Messages & 0 & 0 & 0 & 0 & 89 \\
Cellular Phone Calls & 0 & 0 & 0 & 0 & 89 \\
Telephone Calls & 20 & 2 & 6 & 12 & 48 \\
Letters / Snail Mail & 89 & 0 & 0 & 0 & 0 \\
\hline
\end{tabular}

Table 2 shows that the respondents' parent(s) prefer to communicate with their loved ones using the Internet, in which the different social media application, as well as the email providers, are available. Having access to the Internet at all times makes it possible for more interaction among family members (Alampay, et.al. 2012).

Facebook is still the application commonly used by families nowadays to communicate with one another. Results showed that 84 respondents or $94.3 \%$ use Facebook often or all the time. The result is consistent with statistics showing that Facebook is the most popular social network on the web, with over 2 billion active users monthly worldwide. There are currently 89 million Filipinos using this social media platform (Digital 2021). Facebook has become a key to portraying transnational family life (Madianou, 2016; Madianou and Miller, 2012). It facilitates a state of an always on platform in which there is a continuous flow of information through a various content such as text, photos and videos. (Boyd, 2011), where bonds are established through likes and comments (Madianou, 2016). Same findings were reported by Garinga, et. al. (2018) and Vargas \& Racasa (2018).

The next platform commonly used is Twitter, with 58 respondents or $65.1 \%$ using the application often to all the time. Twitter has 206 million daily active users worldwide as of 
Q2 of 2021. It has 73 million monthly users in the United States and 9 million users in the Philippines as of July 2021 (Statista, 2021). Skype, on the other hand, has not been popular among the respondents. This may be because of the perception that Skype is used for business meetings and not for personal usage.

The use of telephones and cellular phones either to send text messages or to make calls to family members especially those in faraway places are also preferred. These are rich communication media because messages can be relayed immediately. Parents can also hear their children's voice which makes communication more effective.

A more enriched form of media, based on the media richness theory, are email and handwritten letters or snail mail because longer messages can be sent and the risk of misinterpretation are lessened compared to text messages. However, findings show that email is less utilized by the respondents. This can be attributed to the fact that feedback and responses are not immediate using this medium. In the era where both parents and children are busy with their work or studies, there is less time to construct letters or long messages and wait for the reply. The generation today prefers short but frequent messages. This is also evident from the results that none of the respondents and their parents use snail mail any longer. This generation currently use email as their new snail mail, when they want more to share more details or attach files which is not possible with telephone calls.

\subsection{Features of the communication tool used}

Table 3

Features of Communication Tools Used

\begin{tabular}{lccccc}
\hline Communication Tool Features & Never used at all & Rarely & Average & Often & All of the time \\
\hline 1. Messenger/Fb & 0 & 0 & 0 & 0 & 89 \\
2. Video Chat/Fb & 0 & 0 & 0 & 0 & 89 \\
3. Voice Chat/Fb & 0 & 0 & 0 & 0 & 89 \\
4. Email & 1 & 7 & 8 & 7 & 66 \\
5. Land line & 1 & 7 & 11 & 17 & 53
\end{tabular}

As can be clearly seen in Table 3, the features used by the OFW parents are Fb messenger, video chat, and voice chat. Facebook has become the primary means of communication with families from a distance. It is accessible in mobile devices such as 
cellular phones, tablets and laptops. Messenger, video and voice chat are utilized to forge intimacy among family members (Cabalquinto, 2017). By reading the status, browsing photos, and commenting on posts, migrant mothers consider it as distant mothering (Madianou, 2014). They also 'tag' their family members on Facebook photos to symbolize intimacy despite being separated (Cabalquinto, 2018). Using the video call feature of Facebook enables parents to see their children's faces and interact with them more personally. They can tell stories to each other, help with homeworks, talk about grades (Racasa \& Vargas, 2018), show off the latest dance moves to each other on screen. The feeling of still being together is simulated using the video call feature of Facebook. Garinga, et. al. (2018) found that Facebook is used by seafarers to cope with homesickness.

\subsection{Perceived role of communication tool and the degree of closeness in the family}

Table 4

Mode of Communicating with Family

\begin{tabular}{lccc}
\hline \multicolumn{1}{c}{ Indicators } & Never & Sometimes & Always \\
\hline & & & \\
a. I chat with my family on line & 5 & 88 & 1 \\
b. I send and receive messages from my family & 5 & 84 & 0 \\
c. I always update my family in social media & 25 & 64 & 0 \\
d. I send email to my family & 74 & 14 & 1 \\
e. I receive emails from my family & 15 & 70 & 4 \\
\hline
\end{tabular}

As shown in Table 4, the different modes of communicating online with their family are used by the respondents, but not always. Even if they are constantly online or using social media platforms, it does not mean that they always connect with their family. This only shows that efforts to connect with family is initiated by the parent overseas. This can be explained through the Family Systems Theory where a change in the normalcy affects the behavior of the respondents. Their tendency to not always connect with their family abroad is their way of adjusting to the situation. Since chatting, texting and sending emails are less effective media, respondents does not always use these. Moreover, the initiative of the respondents to connect with their overseas parent(s) can also be attributed on the socioeconomic status since they do not always have the money for internet connection or text. 
Table 5

Perceived Degree of Closeness in the Family

\begin{tabular}{llccc}
\hline & \multicolumn{1}{c}{ Indicators } & Knows & Knows & Knows A \\
Nothing & Some & Lot \\
\hline & & 21 & 68 & 0 \\
a. How well do my parents know about my friends & 20 & 50 & 10 \\
b. How well do my parents know about my school work & 18 & 60 & 11 \\
c. How well informed is my family regarding problems/issues & 7 & 77 & 5 \\
d. How well does my family ask to advise in doing family decisions & 58 & 28 & 3 \\
e. How often do I tell my family secrets about myself & & & \\
\hline
\end{tabular}

OFW parents do not know everything about their children (Table 5). Information like their child's friends, school work, problems are not shared with them fully. This is contradictory to Ariate, et.al. (2015) where communication technology makes it easy to maintain a long distance relationship. It is also interesting to note that majority of the respondents does not tell their secrets to their family. Although there are opportunities of communication, children are hesitant to establish an open relationship with their parents. This may be because they do not want their activities to be monitored and controlled by their parents. Social media posts among OFW families can also be interpreted based on an ideal familial image. As explained in the Family Systems Theory, when one side does not conform to what is ideal, it can become a source of tension. The tendency of children is to only post details that will conform to the expectation of their parents. Thus, strategies such as hiding post (Madianou, 2016) or suppressing emotion (Parreñas 2001) can be critical in dealing with family separation. This is referred to as "ambivalent intimacy" (Cabalquinto, 2018).

Time difference may also contribute to the results obtained. As cited by Bernarte et.al., Katz (2004), the possibility of [an OFW parent] calling anytime may be in conflict with the child's availability and vice-versa. Finding a mutual time may be difficult for one or both of them.

Emotional strains of transnational mothering and fathering can include feelings of anxiety, helplessness, loss, guilt, and the burden of loneliness (Parreñas, 2001). Because of this, children conceal problems and secrets that might add to the emotional burden of their parents. Children also regulate their online posts and information that their parents can see, to avoid possible disappointments (Cabalquinto, 2018). 


\subsection{Relationship between the role of communication tools with the perceived Degree of closeness in the family}

The purpose of this research is to find out how the role of ICT in the parent - child relationship relates to the degree of closeness in the family. Overall results show that there is a significant relationship between these variables $(\mathrm{p}$-value $=0.01)$. The relationship in the family becomes closer as parents spend more time communicating online with their children. This result is the same as the findings in the study of Fan \& Chen (2001) and Schrodt et al., (2007) where positive communication was related to the level of openness as well as frequency of communication.

A possible explanation for the low p-value, although positive, may be due to the fact that online communication is mostly initiated by the parents. Even if respondents spend time online, it was not always used to communicate with their parents abroad. The frequency of time spent by the respondents in communicating with their parents may also explain why they do not share more information about themselves. In addition, online communication cannot compare to the impact that face-to-face interactions have on the degree of closeness in the family. Further investigations may be conducted to determine the length of time that is spent online by both parents and child and whether it was utilized for communication.

\section{Conclusion}

From the analysis of data, the results show that laptops and smart phones are the most used ICT tool in communicating with family due to its affordability, mobility and variety of features included. Respondents prefer to use text messaging and online chat over other modes. This result is supported by the media richness theory where rich media such as online chat is more effective than less rich media such as telephone call. OFW parents do not know everything that is happening to their children. Studies claim that respondents do not fully inform their parents about their personal life. This may be due to time difference between families which conflicts with their availability, and / or to avoid emotional stress, tension and disappointments of their parents especially when it comes to problems and decisions.

The results also show that overseas parents and their left-behind children utilizes Facebook as the preferred online platform for communicating while text messaging and calls are used when offline. Using Facebook features such as posts, comments and reactions, chat 
and messaging, members of the family are able to inform each other of their day-to-day activities and experiences. Despite the indications that communication technologies can bridge the gap between transnational families, their online presence may not be sufficient to maintain the parental relationship and degree of closeness compared to their physical presence. Face-to-face interaction is still recommended to sustain parental relationships.

\section{References}

9 Tips on How to Be a Responsible OFW Parent (2019). Pinoy OFW. https://bit.ly/3yKlXrV Alampay, E., Peña - Alampay, L. and Raza, K (2012, September). [Conference Paper] ICTs and Connectedness in Families of Filipino Migrant Workers. IDIA 2012 Conference Istanbul, Turkey. https://bit.ly/3Ay6BY0

Alampay, Erwin \& Raza, Khane \& Rye, Ranjit. (2017). Gender, transnational communication, and aspiration for future overseas work among OFW children. $\begin{array}{llll}\text { Philippine Social } & \text { Sciences }\end{array}$ https://journals.upd.edu.ph/index.php/pssr/article/view/6085

Aparicio, A. (2018), Media Richness Theory: Effects on Communication (2018). https://bit.ly/3fX93PW

Ariate, R. J., Cruz, R., Dimaculangan, J., \& Tibayan, C. A. (2015). The Role of Facebook in Sustaining Relationship Among Families of OFW. Communication Research, 2(1).

Asis, M. (1995), Overseas Employment and Social Transformation in Source Communities: Findings from the Philippines. Asian and Pacific Migration Journal. https://doi.org/10.1177/011719689500400208

Asis. M. (2002), From the Life Stories of Filipino Women: Personal and Family Agendas in Migration. Scalabrini Migration Center. Asian and Pacific Migration Journal. https://doi.org/10.1177/011719680201100104

Asis. M. (2017). The Philippines: Beyond Labor Migration, Toward Development and (Possibly) Return. Migration Information Source. https://bit.ly/3iFVqGE

Bautista, A.G.M. and Tamayo, V.T. (2020) Life Challenges of Overseas Filipino Workers. Open Access Library Journal, 7, 1-9. doi: 10.4236/oalib.1106854.

Bavelas, J, and Segal, L (1982). Family Systems Theory: Background and Implications. Journal of Communication, 32(3), 99-107, https://doi.org/10.1111/j.14602466.1982.tb02503.x

Bernarte, R., Datiles, J., Samson, R., \&Velasco, S. (2015). Reshaping Communication: A Study of How Mediated to Computer Mediated Communication Exchanges Affects 
the Relationship among Overseas Filipino Workers Families. European Academic Research, 2(11). 14197 - 14221. https://bit.ly/2VPu6N8

Boyd, D. (2011). Participating in the always-on lifestyle. In M. Mandiberg (Ed.), The social media reader (pp. 71-76). New York: New York Press

Burns, N. \& Grove, S.K. (2005). The practice of nursing research: Conduct, critique and utilization (5th Ed.). St. Louis, Elsevier Saunders. https://bit.ly/3yHUCXn

Cabalquinto, E. C. (2017). "We're not only here but we're there in spirit": Asymmetrical mobile intimacy and the transnational Filipino family. Mobile Media \& Communication, 6(1), 1-16. https://doi.org/10.1177/2050157917722055

Cabalquinto E.C. (2018). Ambivalent Intimacies: Entangled Pains and Gains Through Facebook Use in Transnational Family Life. In: Dobson A., Robards B., Carah N. (eds) Digital Intimate Publics and Social Media. Palgrave Studies in Communication for Social Change. Palgrave Macmillan, Cham https://doi.org/10.1007/978-3-319$\underline{97607-5 \_15}$

Castro, F. (2016, January 31). Social Media and Digital Stats in the Philippines 2016 (We are Social Data). Retrieved from Third Team Media: https://bit.ly/3AEwjKB

Chen H. (2020). Left-Behind Children as Agents: Mobile Media, Transnational Communication and the Mediated Family Gaze. In: Cabañes J., Uy-Tioco C. (eds) Mobile Media and Social Intimacies in Asia. Mobile Communication in Asia: Local Insights, Global Implications. Springer, Dordrecht. https://doi.org/10.1007/978-94-024-1790-6_9

Clinton, J. \& Hattie, J. (2013) New Zealand students' perceptions of parental involvement in learning and schooling, Asia Pacific Journal of Education, 33:3, 324-337, https://doi.org/10.1080/02188791.2013.786679

Department of Information and Communications Technology (National ICT Household Survey 2019). https://dict.gov.ph/ictstatistics/nicths2019/

Duque, G., San Antonio, D., \& Brazil, L. (2017). A correlational study on social media involvement and parental relationship among students of Asia Pacific College. [Paper Presentation] DLSU Research Congress 2017 De La Salle University, Manila, Philippines. https://bit.ly/3jKSLLg

Dutton, W. (2001). Computers and Society In N. Smelser, P. Baltes (Eds.), International Encyclopedia of the Social \& Behavioral Sciences, 2480-2487. https://doi.org/10.1016/B0-08-043076-7/04321-7

Edwards, O. and Mumford, V. Children Raised by Grandparents: Implications for Social Policy. International Journal of Sociology and Social Policy, 25 (8), 0144-333X. 
Estrada, E. (2015). Mi figue, mi raisin: the Filipinos' culture of migration in the age of globalization. Center for International Relations and Strategic Studies. https://bit.ly/2UXYu86

Fan, X., Chen, M. Parental Involvement and Students' Academic Achievement: A MetaAnalysis. Educational Psychology Review 13, 1-22 (2001). https://doi.org/10.1023/A:1009048817385

Fluellen, J. (2016). Single Mothers of Young Children and Continuing Education. [Doctoral thesis, Warden University] https://bit.ly/3yNPhhm

Garinga, M. L., Laylo, A. L., \& Villareal, C. A. (2018). Filipino Seafarers' Use of Facebook To Cope With Homesickness. LPU-Laguna Journal of International Journal of Tourism and Hospitality Management, 4(1), 1-1.

Graham, E., Jordan, L. P., Yeoh, B. S., Lam, T., Asis, M., \& Su-Kamdi (2012). Transnational families and the family nexus: perspectives of Indonesian and Filipino children left behind by migrant parent(s). Environment \& planning A, 44(4), 10.1068/a4445. https://doi.org/10.1068/a4445

Ha L., Hu X. (2013) Social Media Involvement Among College Students and General Population: Implications to Media Management. In: Friedrichsen M., MühlBenninghaus W. (eds) Handbook of Social Media Management. Media Business and Innovation. Springer, Berlin, Heidelberg. https://doi.org/10.1007/978-3-642-28897$\underline{5 \_44}$

Ho, A. (2011). OFWs make Philippines Asia's most hi-tech. Inquirer,Net. https://bit.ly/3fYWlQG

Madianou, M. and Miller, D. (2011, May) Mobile phone parenting: Reconfiguring relationships between Filipina migrant mothers and their left-behind children. New Media \& Society 13(3) , 457-470. https://doi.org/10.1177/1461444810393903

Madianou, M. (2012). Migration and the accentuated ambivalence of motherhood: The role of ICTs in Filipino transnational families. Global Networks, 12(3), 277-295 http://dx.doi.org/10.1111/j.1471-0374.2012.00352.x

Madianou, M. (2016). Ambient co-presence: Transnational family practices in polymedia environments. Global Networks, 16(2), 183-201. https://doi.org/10.1111/glob.12105

Madianou, M., \& Miller, D. (2012). Migration and new media: Transnational families and polymedia. Abingdon, OX: Routledge.

Mao, M., Zang, L., \& Zhang, H. (2020). The Effects of Parental Absence on Children Development: Evidence from Left-Behind Children in China. International Journal of Evironmental Research and Public Health, 17(18), 6770. https://doi.org/10.3390/ijerph17186770 
Marchetta, F. \& Sokcheng Sim, (2021) The effect of parental migration on the schooling of children left behind in rural Cambodia, World Development, 146, https://doi.org/10.1016/j.worlddev.2021.105593

McKay, D. (2007). 'Sending dollars shows feeling'-Emotions and Economies in Filipino Migration, Mobilities, 2:2, 175-194, https://doi.org/10.1080/17450100701381532

Media Releases: Personal and Cash Remittances Set Record Highs in 2019 at US\$33.5 Billion and US\$30.1 Billion (2020). Bangko Sentral ng Pilipinas. https://bit.ly/3iHzUkR

Moreau, E. (2020). The Top Social Networks People Are Using Today. https://bit.ly/3g0m1fR

OFWs use Internet, not landlines, to keep in touch. (2012, January) $A B S-C B N$ News. https://bit.ly/3jS3T9i

Otani, M. (2020) Parental involvement and academic achievement among elementary and middle school students. Asia Pacific Educ. Rev. 21, 1-25. https://doi.org/10.1007/s12564-019-09614-z

Parreñas, R. S. (2001). Mothering from a distance: Emotions, gender, and intergenerational relations in Filipino transnational families. Feminist Studies, 27(2), 361-390. https://doi.org/10.2307/3178765

Racasa, A. \& Vargas, D. (2021). Analysis of Communication Patterns Among College Student with Overseas Foreign Workers (OFW) Family Through the use of Social Media. SSRN 3785383. http://dx.doi.org/10.2139/ssrn.3785383

Revised POEA Rules and Regulations Governing the Recruitment and Employment of Landbased Overseas Filipino Workers Of 2016. Part 1 Rule II. Definition of Terms. p.2.

Runcan, P., Constantineanu, C., Ielics, B., \& Popa, D. (2012). The Role of Communication in the Parent-Child Interaction, Procedia - Social and Behavioral Sciences, 46, 904-908, https://doi.org/10.1016/j.sbspro.2012.05.221

Samonte P. (2019) "Long-Distance Parenting": A Media Ecological Study on Values Communication Between Migrant Parents and Their Children in Paete, Laguna. In: Dutta M., Zapata D. (eds) Communicating for Social Change. Palgrave Macmillan, Singapore. https://doi.org/10.1007/978-981-13-2005-7_7

Santos, A., (2014) Philippines: A History of Migration. Pulitzer Center. https://bit.ly/37Dcmr3

Schrodt, P, Ledbetter, A., \& Ohrt, J. (2007) Parental Confirmation and Affection as Mediators of Family Communication Patterns and Children's Mental Well-Being, Journal of Family Communication, 7(1), 23-46, https://doi.org/10.1080/15267430709336667 
Shih, Kristy Y. (2016). Transnational Families. The Wiley Blackwell Encyclopedia of Family Studies, https://doi.org/10.1002/9781119085621.wbefs177

Statista Research Department. (2021). Statistics and Facts about social media usage in the Philippines. https://bit.ly/3iHzUkR

Teguihanon, J., Cuaton, G. (2020). Overseas Filipino Workers in Poland: Maternal Migration and its Effects on Children and Families Left Behind. Regional Journal of Southeast Asian Studies. 5 (1).

TNS Digital Life 2012 confirms higher reach of digital versus radio and print (2012). PR News. https://bit.ly/3jWKwMq

Total Number of OFWs Estimated at 2.2 Million. (2020). Philippine Statistics Authority. https://bit.ly/2Xfrglk

Uy-Tioco, C., (2007). Overseas Filipino Workers and Text Messaging: Reinventing Transnational Mothering. Journal of Media \& Cultural Studies 21(2):253-265. https://doi.org/10.1080/10304310701269081

Wang, M., Chu, J., Viswanath, K., Wan, A., Lam, T, \& Chan, S. (2015). Using Information and Communication Technologies for Family Communication and Its Association With Family Well-Being in Hong Kong: FAMILY Project. Journal of Internet Medical Research, https://doi.org/10.2196/jmir.4722

Weinberger, D. (2020). 7 Reasons To Keep Your Landline. https://bit.ly/3yIScbh

Yeung, J., and Bacani, X., (2020) When Love is Not Enough. Cable News Network. https://cnn.it/3sdiv6H 